\title{
Effects of group size on schooling behavior in two cyprinid fish species
}

\author{
Shi-Jian Fu* \\ Laboratory of Evolutionary Physiology and Behavior, Chongqing Key Laboratory of Animal Biology, \\ Chongqing Normal University, Chongqing, 400047, PR China
}

\begin{abstract}
Group living is a commonly observed phenomenon in fish species in nature while the benefits and costs of group living may vary among species with different habitats. To test whether the properties of schools and individual response to group size vary between fish species, I used juveniles of 2 closely related group-living cyprinids as an experimental model: Chinese bream Parabramis pekinensis, which prefer still water and display high levels of aggression, and qingbo Spinibarbus sinensis, which prefer flowing water and are relatively unaggressive. I videoed both species in groups of 2,4 and 8 individuals at $25^{\circ} \mathrm{C}$. Their motion and the spatial structure of the schools were then analyzed, mostly using an automated tracking program. In general, qingbo showed higher spontaneous swimming speeds than Chinese bream, but both species showed increased swimming speed with increased group size, possibly due to increased boldness and decreased vigilance when in larger groups. The nearest neighbor distance decreased with the increase in group size in both species. The synchronization of swimming speeds and the separation swimming angle between individuals decreased with increasing group size in Chinese bream but remained the same in qingbo. The higher synchronization of swimming between qingbo and the relatively random distribution of group members within the schools compared to those of Chinese bream schools suggest that qingbo are more adapted to group living than Chinese bream, which is possibly due to differences in their preferred habitats and/or the structure of their social hierarchy.
\end{abstract}

KEY WORDS: Group size $\cdot$ School structure $\cdot$ Collective behavior $\cdot$ Costs and benefits

\section{INTRODUCTION}

Any group of fish that stays together is considered to be shoaling, and if the group swims in the same direction in a coordinated manner, it is said to be schooling (Pitcher \& Parrish 1993, Delcourt \& Poncin 2012). Schooling is a commonly observed phenomenon in fish species, and about one-half of all fish species school for part or all of their lives (Shaw 1978). Fish derive many benefits from living in groups, including defense against predators, enhanced foraging success and improved swimming efficiency (Hemelrijk et al. 2015). However, fish in the field do not always choose to stay in large groups, suggesting that the benefits of group living are offset by certain costs. For example,

${ }^{*}$ Corresponding author: shijianfu9@cqnu.edu.cn the foraging efficiency of schooling may shift from a benefit to a cost if food availability is low due to competition. Another potential cost of schooling behavior includes the energy expended in maintaining a position within the group. Furthermore, hierarchal structures and other social conflicts might also set an upper limit to group size (Wong 2011). Thus, different species of fish might prefer a specific group size, which could vary for species occupying habitats with different water flow patterns, food distribution pattern and predation stress. For example, fish species in flowing water may prefer living in groups with larger group size compared to those from still-water habitat, since swimming in a group can enhance speed and save power (Becker et al. 2015).

() The author 2016. Open Access under Creative Commons by Attribution Licence. Use, distribution and reproduction are unrestricted. Authors and original publication must be credited. 
How the behavior of individuals, and the interactions between them, influence group-level behaviors is at the heart of collective behavioral research. Collective motion, where group members move in synchrony, is achieved when individuals adopt rules for interactions that determine how they respond to their neighbors' movements and positions (Herbert-Read et al. 2011). Because of these interaction rules, group size has been found to have a profound effect on school properties (Herbert-Read et al. 2013, Shelton et al. 2015). The most frequently studied school properties include cohesion, which is usually indicated by the nearest neighbor distance (NND), and coordination, which is indicated by the synchronization of swimming activity and the polarity of orientation within the school. It has been found that the ecological benefits and costs of group behavior associated with a specific property of the school varies with species and group size (Gimeno et al. 2016, Suriyampola et al. 2016a) Investigation in fish species also found that water flow showed a profound effect on school properties such as cohesion (Suriyampola et al. 2016b) and polarization (Chicoli et al. 2014). Thus, further investigation on whether group size has different effects on school traits among fish species that prefer different flow regimes may yield interesting results.

Radakov (1973) considered fish within schools as being behaviorally identical and interchangeable with regard to their position, i.e. even though positions shift frequently among group members, the positions occupied by group members are random. However, the positions that individuals take relative to others within groups may have important evolutionary and ecological consequences as there may be both benefits and costs associated with different positions (Krause \& Ruxton 2002). Differences among individuals, such as age, nutritional status, and sex, may all influence the position adopted by an individual within a group. Individuals within groups may therefore be expected to modify their positions relative to their neighbors as a function of their internal state. There are consistent inter-individual differences in physiology and behavior within species (Biro \& Stamps 2010). Chicoli et al. (2014) found that water velocity had a profound effect on school structure. Thus, investigations into whether the locations of individual fish in a school show a heterogeneous spatial organization and whether there is a relationship of this organization with group size and/or preferred water regime could provide interesting information for understanding schooling behaviour.

In the present study, I aimed to test the hypothesis that school properties and individual response to group size vary between fish species that preferred different habitats. To test this hypothesis, I selected juveniles of 2 closely related cyprinids as experimental animals: the Chinese bream Parabramis pekinensis, a species that prefers living in still water, and qingbo Spinibarbus sinensis, a species that is generally found in rapidly flowing water (Yan et al. 2013). It has been demonstrated that current speed has profound effects on school properties and structure as well as the energy expended in swimming (Fu et al. 2013, Yan et al. 2013, Chicoli et al. 2014, Becker et al. 2015; Suriyampola et al. 2016b). Thus I anticipated differences in the schooling properties and individual response to group size between these 2 fish species, even in still water. To achieve these goals, I videoed both species in groups of 2, 4 and 8 individuals, and the motion and spatial structure of the schools were analyzed.

\section{MATERIALS AND METHODS}

\section{Experimental fish and holding conditions}

Juvenile Chinese bream Parabramis pekinensis and qingbo Spinibarbus sinensis (see Table 1 for body sizes) were obtained from a local fish farm. The fish were maintained in dechlorinated fresh water in the recirculating water rearing system at Chongqing Normal University for $2 \mathrm{wk}$ prior to the experiment. Water temperature was maintained at $25.0 \pm 0.5^{\circ} \mathrm{C}$ and the dissolved oxygen level at $>90 \%$ saturation. The photoperiod was $12 \mathrm{~h}: 12 \mathrm{~h}$ light:dark. One-tenth of the water was replaced daily with freshwater to maintain water quality. Throughout the experimental period, the fish were fed daily to satiation with commercial feed until $48 \mathrm{~h}$ before the experimental trials. No sacrifice was conducted during the experiments and all experimental fish were returned to the hatchery.

Table 1. Body size of the experimental fish (mean $\pm \mathrm{SE}, \mathrm{N}=12$ )

\begin{tabular}{|c|c|c|c|c|}
\hline \multirow[t]{2}{*}{ Group size } & \multicolumn{2}{|c|}{ Chinese bream -} & \multicolumn{2}{|c|}{ Q Qingbo } \\
\hline & $\begin{array}{l}\text { Body mass } \\
\text { (g) }\end{array}$ & $\begin{array}{l}\text { Body length } \\
\text { (cm) }\end{array}$ & $\begin{array}{l}\text { Body mass } \\
\text { (g) }\end{array}$ & $\begin{array}{c}\text { Body length } \\
\text { (cm) }\end{array}$ \\
\hline 2 & $3.27 \pm 0.20$ & $5.89 \pm 0.11$ & $3.86 \pm 0.13$ & $5.77 \pm 0.07$ \\
\hline 4 & $3.25 \pm 0.12$ & $5.95 \pm 0.07$ & $4.03 \pm 0.10$ & $5.69 \pm 0.06$ \\
\hline 8 & $3.48 \pm 0.08$ & $5.94 \pm 0.05$ & $4.44 \pm 0.17$ & $5.94 \pm 0.15$ \\
\hline Significance & $\begin{array}{c}F_{2,33}=0.901 \\
\mathrm{p}=0.416\end{array}$ & $\begin{array}{c}F_{2,33}=0.180 \\
\mathrm{p}=0.836\end{array}$ & $\begin{array}{c}F_{2,33}=2.687 \\
\mathrm{p}=0.084\end{array}$ & $\begin{array}{c}F_{2,33}=1.597 \\
\mathrm{p}=0.218\end{array}$ \\
\hline
\end{tabular}




\section{Experimental arena, data collection and parameter calculations}

Fish were used only once in any experimental trial. Twelve replicates of each group size (groups of 2,4 , and 8 individuals) for Chinese bream and qingbo ( $\mathrm{N}=168$ for each species) were recorded in a round experimental arena (diameter $100 \mathrm{~cm}$, depth $25 \mathrm{~cm}$ ), which was made of $1 \mathrm{~cm}$ thick acrylic and was filled to a depth of $7 \mathrm{~cm}$ with dechlorinated water. The arena was lit with fluorescent lights and isolated using an opaque plastic curtain to prevent external visual disturbances to the fish. A webcam (Logitech Pro 9000) placed directly over the arena was used to record the movements of each group of fish for $15 \mathrm{~min}$ (30 frames per second) after they were transferred to the arena. Videos were converted from the .wmv to avi format using Format Factory (http://format-factory.softonic.cn) and imported to an automated tracking program, idTracker (v 2.1) (see Pérez-Escudero et al. 2014 for a full description of the tracking software). This program automatically tracked the position of each fish in every frame of the video for each 15 min trial, resulting in $27000 x$ and $y$ coordinates of each fish in each video. To eliminate the influence on the data of handling stress, only the coordinates from minutes 6 to 15 were used for the analysis of the experimental parameters. The $x$ and $y$ coordinates of each pixel were converted into $\mathrm{cm}$ (Miller \& Gerlai 2012b; Killen et al. 2016). The calculations of the tested parameters are described below and are according previous studies (see review in Delcourt \& Poncin 2012). The following parameters of each individual or each pair of individuals were measured and the mean of all individuals or all pairs were then calculated for each repetition.

Instantaneous speed $\left(v, \mathrm{~cm} \mathrm{~s}^{-1}\right)$ :

$$
v(t)=\sqrt{(x(t)-x(t-1))^{2}+(y(t)-y(t-1))^{2}} / d
$$

where $x(t)$ and $y(t)$ are the $x$ and $y$ coordinates of each fish at time $t$, and $d$ is the length of the time interval (i.e. $1 / 30$ s).

Synchronization of speed $\left(S_{\mathrm{v}}, \%\right)$ :

$$
S_{V}=1-\left|\frac{v_{1}-v_{2}}{v_{1}+v_{2}}\right|
$$

where $v_{1}$ and $v_{2}$ are the instantaneous speed of each pair of individuals within a given group.

Distance $(D, \mathrm{~cm})$ :

$$
D(t)=\sqrt{\left(x_{1}(t)-x_{2}(t)\right)^{2}+\left(y_{1}(t)-y_{2}(t)\right)^{2}}
$$

where $x(t)$ and $y(t)$ are the $x$ and $y$ coordinates of the each pair of fish individuals.

Separation swimming angle (SSA, rad) was used as the indicator of group polarity, which is the angular difference between vector angles of each pair of individuals within a given group. The vector angle $(A)$ was calculated as follows:

$$
A=\arctan \left(\frac{y(t)-y(t-1)}{x(t)-x(t-1)}\right)
$$

To measure the characteristics of each school's spatial structure, 360 frames were selected from the 18000 frames (i.e. $2 \%$ of the frames) and one individual was randomly selected from each repetition as the focal fish. The focal fish was identified as swimming at the front of the school using 2 criteria, i.e. it swam ahead of its school members and either the $x$ or $y$ coordinate showed the smallest or largest value among all group members. The percentage of time the focal fish swam in the front of the group $\left(P_{\mathrm{f}}, \%\right)$ was calculated as follows:

$$
P_{\mathrm{f}}=\frac{F_{\mathrm{o}}}{F_{\mathrm{T}}} \times 100 \%
$$

where $F_{\mathrm{o}}$ is the number of frames in which the focal fish was swimming at the front of the group, and $F_{\mathrm{T}}$ is the total number of the visually measured frames.

\section{Data analysis}

SPSS statistics v20.0 (SPSS and IBM) was used to perform the data analysis. $\mathrm{p}$-values $<0.05$ were considered statistically significant, and all data are presented as the mean $\pm \mathrm{SE}$. The effects of group size and species on the measured parameters were examined using a 2-way ANOVA. The ANOVA was followed by Duncan's multiple range tests or $t$-tests if statistical comparisons of the values from groups of different sizes or different species were necessary. A binomial test for nonparametric data was used to determine if the percentage of time a given focal fish swam in the front of its group was significantly different from the anticipated percentage.

\section{RESULTS}

\section{Spontaneous swimming speed}

There was no significant difference in body size among the different group sizes of a species (Table 1). Both species and group size showed significant 
effects on swimming speed $(\mathrm{p}<0.001)$ (Table 2$)$, and qingbo Spinibarbus sinensis had a significantly higher swimming speed than Chinese bream Parabramis pekinensis at all group sizes $(\mathrm{p}<0.001)$ (Fig. 1A). For Chinese bream, the maximum swimming speed was recorded in 4-individual groups, which had significantly higher values than the other 2 group sizes. In contrast, the maximum swimming speed for qingbo was recorded in the 8-individual groups, which was significantly higher than the values of the other 2 group sizes, and the swimming speed of 4 -individual groups was also significantly higher than that of the 2 -individual groups $(\mathrm{p}<0.05)$.

\section{Synchronization of speed}

Both species and group size showed significant effects on synchronization of swimming speed $(p<$ 0.001). Chinese bream showed significantly lower degrees of synchronization of speed than were observed in qingbo across all group sizes $(p<0.001)$ (Fig. 1B). The synchronization of speed increased with group size in Chinese bream, whereas it showed no change in qingbo among different group sizes.

\section{Nearest neighbor distance (NND)}

The NNDs in 4- and 8-individual groups were significantly shorter than those of 2-individual groups in both Chinese bream and qingbo ( $<0.001)$, and there was no significant difference between the 2 species within each group size (Fig. 1C).

\section{Separation swimming angle (SSA)}

Qingbo showed no significant variation in SSA among the different group sizes, whereas the SSA of 8-individual group was significantly lower than that of the 2- and 4-individual groups in Chinese bream $(\mathrm{p}<0.05)$ (Fig. 1D). There was no significant difference between the 2 species within each group size.

\section{Percentage of time the focal fish swam in the front of the group $\left(P_{\mathrm{f}}\right)$}

Qingbo showed a relatively random distribution of group members within the schools compared to Chinese bream (Fig. 2). For Chinese beam, all 12 focal fish in the 2-individual groups and 11 out of 12 focal fish in the 4- and 8-individual groups showed significant differences in $P_{\mathrm{f}}$ from the anticipated percentage. Furthermore, 1 (the 4th), 3 (the 4th, 5th and 6th) and 4 (the 5th, 6th, 9th and 11th) focal fish out of the 12 individuals from the 2-, 4- and 8-individual groups, respectively, of Chinese bream never appeared in the front of a group. In qingbo, 6, 9 and 10 focal fish out of the 12 repeated trials showed significant differences in $P_{\mathrm{f}}$ from the anticipated percentage. Furthermore, 1 focal fish out of the 12 individuals from 2-, 4- and 8-individual groups (the 6th, 12th and 1st, respectively) of qingbo never appeared in the front of the group.

\section{DISCUSSION}

\section{Effect of group size on spontaneous swimming performance}

Chinese bream Parabramis pekinensis showed lower swimming speeds than qingbo Spinibarbus sinensis, which may be due to the differences between the natural habitats of these 2 species; qingbo prefer to live in rapidly flowing water, whereas Chinese bream prefer to live in still water (Yan et al. 2013). With increase in group size, both species

Table 2. Effect of group size and species on the measured variables, based on a 2-way ANOVA. *Significantly different (p < 0.05). See Fig. 1 for more details

\begin{tabular}{|lcccc|}
\hline & Speed & $\begin{array}{c}\text { Synchronization } \\
\text { of speed }\end{array}$ & $\begin{array}{c}\text { Nearest neighbor } \\
\text { distance }\end{array}$ & Polarity \\
\hline Group size effect & $F_{2,66}=26.44$ & $F_{2,66}=3.912$ & $F_{2,66}=14.85$ & $F_{2,66}=4.062$ \\
& $\mathrm{p}<0.001^{*}$ & $\mathrm{p}=0.025^{*}$ & $\mathrm{p}=0.022^{*}$ \\
Species effect & $F_{1,66}=235.5$ & $F_{1,66}=21.38$ & $F_{1,66}=0.023$ & $F_{1,66}=0.000$ \\
& $\mathrm{p}<0.001^{*}$ & $\mathrm{p}<0.001^{*}$ & $\mathrm{p}=0.880$ & $\mathrm{p}=0.987$ \\
$\mathrm{G} \times \mathrm{S}$ & $F_{2,66}=20.73$ & $F_{2,66}=2.208$ & $F_{2,66}=0.098$ & $F_{2,66}=4.416$ \\
& $\mathrm{p}<0.001^{*}$ & $\mathrm{p}=0.118$ & $\mathrm{p}=0.907$ & $\mathrm{p}=0.016^{*}$ \\
\hline
\end{tabular}



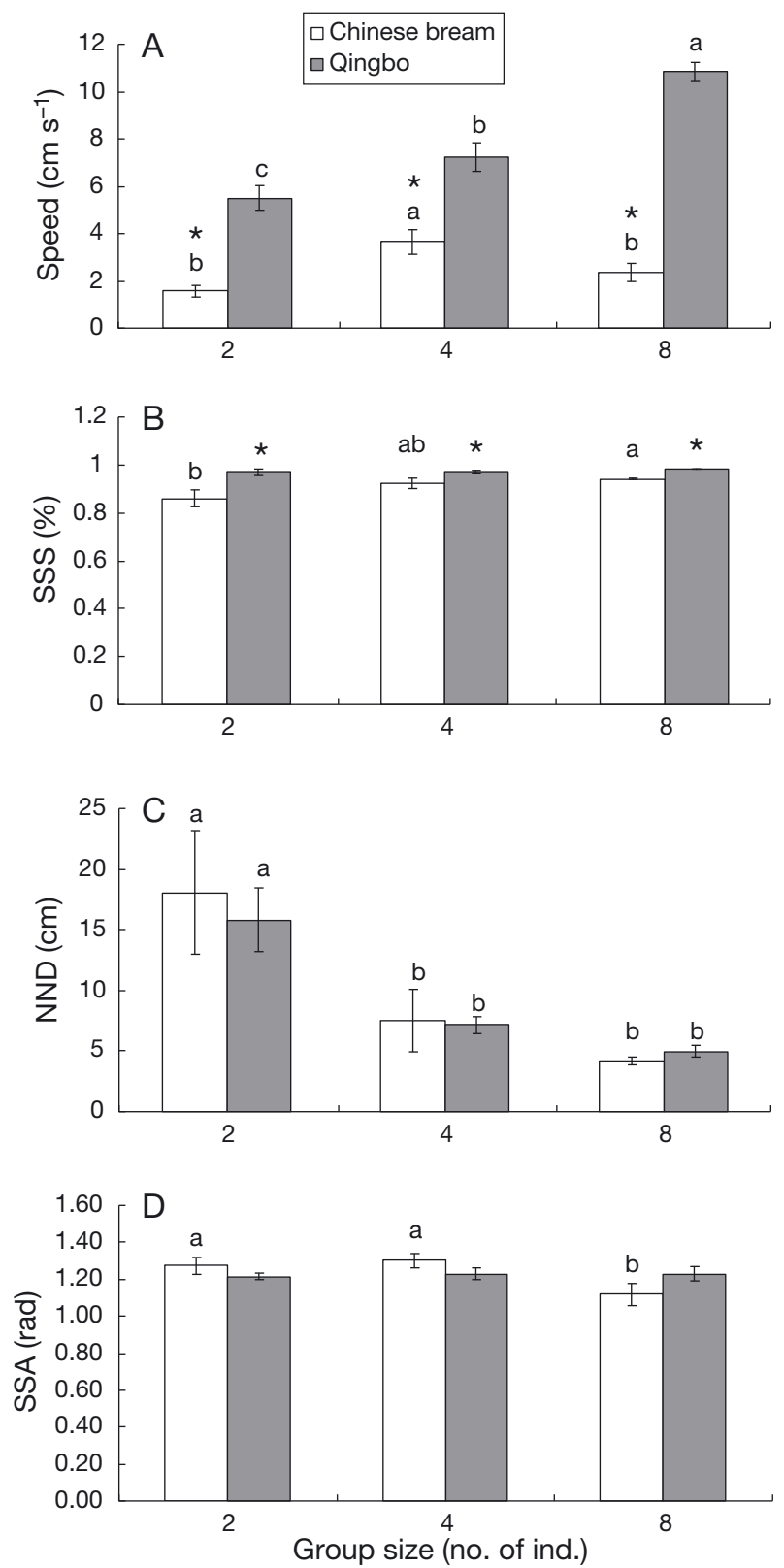

Fig. 1. Effect of group size on (A) swimming speed, (B) synchronization of swimming speed (SSS), (C) nearest neighbor distance (NND) and (D) the separation swimming angle (SSA) of a given group in Chinese bream and qingbo (mean $\pm \mathrm{SE}, \mathrm{N}=12$ ). ${ }^{*}$ Significant difference between 2 species within a specific group size $(\mathrm{p}<0.05)$. Different letters above bars: significant differences among different group sizes within each species $(p<0.05)$

showed increased activity levels and hence higher swimming speeds. The increased activity levels may be partially explained by increases in boldness and/or decreases in vigilance, allowing more time and energy to be spent on other routine swimming activities, such as foraging, exploration and patrolling, as well as by the stimulation of observing the swimming behavior of their neighbors (Grand \& Dill 1999, Mathiron et al. 2015). However, previous studies on barred flagtails Kuhlia mugil found that spontaneous swimming speed decreased with increased group size in association with improved coordination of the school's behavior and an increase in the efficiency of receiving useful environmental information (Gautrais et al. 2012). Nevertheless, spontaneous activity has been studied frequently as an important indicator of the foraging mode of fish species (Fu et al. 2009). However, most studies have measured the spontaneous activities of experimental fish individually (Fu et al. 2009). The present study suggests that group size is an important factor that should be considered in future investigations of spontaneous activities of fish.

\section{Effect of group size on coordination and cohesion}

In the present study, both qingbo and Chinese bream schools showed high synchronization of speed and high polarity, as shown by the SSA values. The results indicate that schools of these 2 cyprinids show a high level of coordination among group members. These results agree with field observations showing that both species prefer living in groups, in rivers (qingbo) or still water (Chinese bream) (Killen et al. 2016). It is worth noting that the present study was performed in still water and that school polarity might be profoundly increased in flowing water. The synchronization of speed increased while SSA decreased in Chinese bream in 8-individual groups, possibly due to the fact that most Chinese bream do not swim in 2- or 4-individual groups (Killen et al. 2016). However, a higher percent of synchronization of swimming speeds in qingbo than in Chinese bream might suggest qingbo swim with greater coordination than Chinese bream. A decreased synchronization of speed has been found in mosquito fish Gambusia affinis (Herbert-Read et al. 2013) and giant danio Danio aequipinnatus (Viscido et al. 2004) with increasing group size, whereas walleye pollock Theragra chalcogramma show no change in synchronization of speed which is similar to the findings for qingbo in the present study (Sogard \& Olla 1997). The reason for these species-specific differences in schooling tendencies may be due to the difference in their preferred habitats or the hierarchical structure of their schools (Miller \& Gerlai 2012a). On the one hand, flowing water may induce a more active pace of life and greater coordination when swimming in 

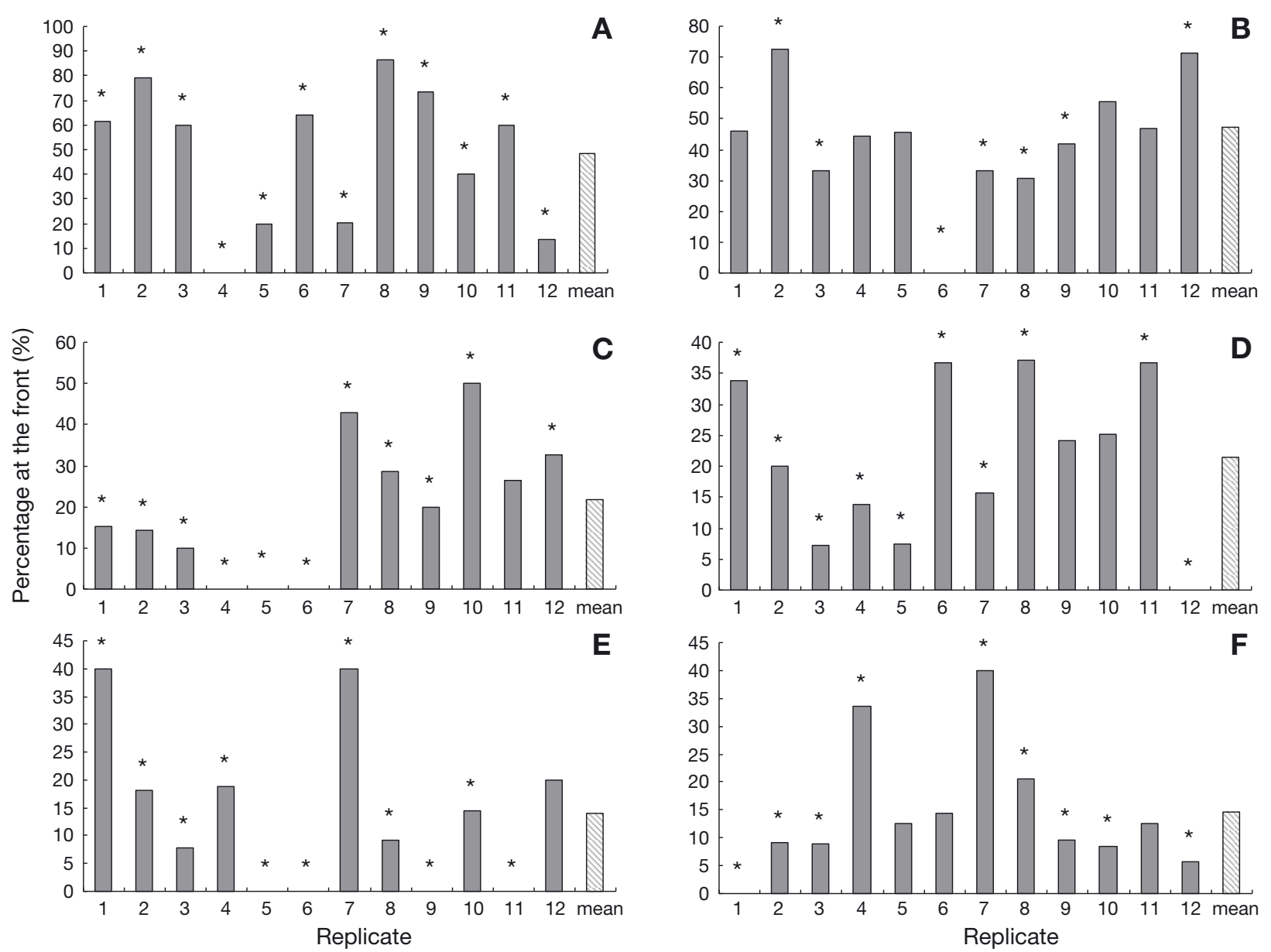

Fig. 2. Percentage of time a given focal fish swam in the front of its group (i.e. the percentage of time it swam as a leader) in different-sized groups of $(\mathrm{A}, \mathrm{C}, \mathrm{E})$ Chinese bream and $(\mathrm{B}, \mathrm{D}, \mathrm{F})$ qingbo in groups of $(\mathrm{A}, \mathrm{B}) 2$ individuals, $(\mathrm{C}, \mathrm{D}) 4$ individuals and $(\mathrm{E}, \mathrm{F}) 8$ individuals. ${ }^{*}$ Significant difference from expected percentages (i.e. $50 \%$ in 2 -individual groups, $25 \%$ in 4 -individual groups, and $12.5 \%$ in 8 -individual groups)

schools than is observed in still-water species such as Chinese bream. On the other hand, Chinese bream show much higher levels of aggressive behavior compared to Chinese bream, which might reduce the synchronization of their swimming behavior (Hess et al. 2016).

In addition to school coordination, school cohesion, as indicated by NNDs, is another important grouplevel trait that has been examined in studies of fish schools. In the present study, NNDs decreased in both Chinese bream and qingbo, suggesting that cohesion increases with increasing group size in both species. This has been frequently documented in group-living fish species such as zebrafish Danio rerio, white cloud mountain minnows Tanichthys albonubes, tiger barbs Barbus tetrazona, angelfish Pterophyllum scalare and neon tetras Paracheirodon innesi (Saxby et al. 2010, Shelton et al. 2015). However, the swimming speed of qingbo was much higher than that of Chinese bream, and most possibly, the distances between individuals increased with swimming speed in order to avoid collision.

\section{Distribution of focal fish}

Most focal fish showed a significant difference in the percentage of time spent swimming in the front of a group than estimated based on a random distribution, which may suggest different internal states, social hierarchies and/or social roles among group members in both species. These findings agree with the studies on golden shiners Notemigonus crysoleucas, which found that in some cases the lead positions were consistently occupied by the same individuals (Reebs 2000). It has been found that hungry individuals tend to lead more often, presumably because this allows them to find food first (Krause \& Ruxton 
2002) even though it may also expose them more to predators (Bumann et al. 1997). However, researchers have also argued that, although there may be leaders in the sense that the same individuals are always found at the front (Mazeroll \& Montgomery 1995), the overall movement of the whole group is not necessarily determined by them (Krause et al. 2000). Nevertheless, the present study demonstrated differences in the positions occupied by group members within the structure of the school. Whether such differences are consistent and, if they are, the nature of the relationship between the position occupied and the internal state of a group member and/or the ecological benefits and costs of different positions deserves further investigation.

The significant difference in the percentage of time spent swimming in the front among group members was more obvious in Chinese bream than qingbo. For example, in both 4- and 8-individual groups, 3 Chinese bream never appeared at the front whereas this was the case for only one individual in qingbo. Furthermore, 2 Chinese bream individuals swam at the front with $P_{\mathrm{f}}>40 \%$ whereas no qingbo showed such a high proportion. This may be due to the fact that Chinese bream usually show much more aggressive behavior, hence a stable social hierarchy, than qingbo.

\section{CONCLUSION}

In conclusion, qingbo Spinibarbus sinensis generally showed higher spontaneous activity levels than Chinese bream Parabramis pekinensis, but both species showed increased swimming speeds with increasing group size, possibly due to increased boldness and decreased vigilance associated with larger groups. The high polarity and increased cohesion (indicated by decreased NNDs) observed with larger groups in both species agree with the observations of their schooling behaviour in the wild. However, the higher synchronization of swimming amongst qingbo and the relatively random distribution of group members within the schools compared to those of Chinese bream schools suggest that qingbo are more adapted to schooling than Chinese bream, which is possibly due to differences in their preferred habitats and/or the structure of their social hierarchy.

Acknowledgements. This study was approved by Animal Care and Use Committee of Key Laboratory of Animal Biology of Chongqing (Permit Number: Zhao-20140721-01) and performed in strict accordance with the recommendations in the Guide for the Care and Use of Animal at the Key Labo- ratory of Animal Biology of Chongqing, China. This study was funded by the National Science Foundation of China (NSFC 31670418).

\section{LITERATURE CITED}

Becker AD, Masoud H, Newbolt JW, Shelley M, Ristroph L (2015) Hydrodynamic schooling of flapping swimmers. Nat Commun 6:8514

*Biro PA, Stamps JA (2010) Do consistent individual differences in metabolic rate promote consistent individual differences in behavior? Trends Ecol Evol 25:653-659

Bumann D, Rubenstein D, Krause J (1997) Mortality risk of spatial positions in animal groups: the danger of being in the front. Behaviour 134:1063-1076

Chicoli A, Butail S, Lun Y, Bak-Coleman J, Coombs S, Paley DA (2014) The effects of flow on schooling Devario aequipinnatus: school structure, startle response and information transmission. J Fish Biol 84:1401-1421

* Delcourt J, Poncin P (2012) Shoals and schools: back to the heuristic definitions and quantitative references. Rev Fish Biol Fish 22:595-619

F Fu SJ, Zeng LQ, Li XM, Pang X, Cao ZD, Peng JL, Wang YX (2009) The behavioural, digestive and metabolic characteristics of fishes with different foraging strategies. J Exp Biol 212:2296-2302

* Fu SJ, Cao ZD, Yan GJ, Fu C, Pang X (2013) Integrating environmental variation, predation pressure, phenotypic plasticity and locomotor performance. Oecologia 173: 343-354

Gautrais J, Ginelli F, Fournier R, Blanco S, Soria M, Chaté H, Theraulaz G (2012) Deciphering interactions in moving animal groups. PLOS Comput Biol 8:e1002678

* Gimeno E, Quera V, Beltran FS, Dolado R (2016) Differences in shoaling behavior in two species of freshwater fish (Danio rerio and Hyphessobrycon herbertaxelrodi). J Comp Psychol 130:358-368

*Gand TC, Dill LM (1999) The effect of group size on the foraging behaviour of juvenile coho salmon: reduction of predation risk or increased competition? Anim Behav 58: 443-451

*Hemelrijk CK, Reid DAP, Hildenbrandt H, Padding JT (2015) The increased efficiency of fish swimming in a school. Fish Fish 16:511-521

* Herbert-Read JE, Perna A, Mann RP, Schaerf TM, Sumpter DJ, Ward AJ (2011) Inferring the rules of interaction of shoaling fish. Proc Natl Acad Sci USA 108:18726-18731

*Herbert-Read JE, Krause S, Morrell LJ, Schaerf TM, Krause J, Ward AJ (2013) The role of individuality in collective group movement. Proc R Soc B 280:20122564

*Hess S, Fischer S, Taborsky B (2016) Territorial aggression reduces vigilance but increases aggression towards predators in a cooperatively breeding fish. Anim Behav 113:229-235

*Killen SS, Fu C, Wu QY, Fu SJ (2016) The relationship between metabolic rate and sociability is altered by food deprivation. Funct Ecol 2016:1358-1365

Krause J, Ruxton GD (2002) Living in groups. Oxford University Press, New York, NY

Krause J, Hoare D, Krause S, Hemelrijk CK, Rubenstein DI (2000) Leadership in fish shoals. Fish Fish 1:82-89

Mathiron AGE, Crane AL, Ferrari MCO (2015) Individual vs. social learning of predator information in fish: Does group size affect learning efficacy? Behav Ecol Sociobiol 69:939-949 
Mazeroll AI, Montgomery WL (1995) Structure and organization of local migrations in brown surgeonfish (Acanthurus nigrofuscus). Ethology 99:89-106

Miller N, Gerlai R (2012a) From schooling to shoaling: patterns of collective motion in zebrafish (Danio rerio). PLOS ONE 7:e48865

Miller N, Gerlai R (2012b) Automated tracking of zebrafish shoals and the analysis of shoaling behavior. In: Kalueff AV, Stewart AM (eds) Zebrafish protocols for neurobehavioral research. Humana Press, New York, NY, p 217-230

Pérez-Escudero A, Vicente-Page J, Hinz RC, Arganda S, Gonzalo G de Polavieja (2014) idTracker: tracking individuals in a group by automatic identification of unmarked animals. Nature Methods 11:743-748

Pitcher TJ, Parrish JK (1993) Functions of shoaling behavior in teleosts. In: Pitcher TJ (ed) Behaviour of teleost fishes, 2nd edn. Chapman \& Hall, London, p 363-439

Radakov DV 1973. Schooling in the ecology of fish. Wiley, New York, NY

Reebs SG (2000) Can a minority of informed leaders determine the foraging movements of a fish shoal? Anim Behav 59:403-409

Saxby A, Adams L, Snellgrove D, Wilson RW, Sloman KA (2010) The effect of group size on the behaviour and welfare of four fish species commonly kept in home aquaria.

Editorial responsibility: Victor Benno Meyer-Rochow, Oulu, Finland
Appl Anim Behav Sci 125:195-205

Shaw E (1978) Schooling fishes. Am Sci 66:166-175

* Shelton DS, Price BC, Ocasio KM, Martins EP (2015) Density and group size influence shoal cohesion, but not coordination in zebrafish (Danio rerio). J Comp Psychol 129:72-77

Sogard SM, Olla BL (1997) The influence of hunger and predation risk on group cohesion in a pelagic fish, walleye pollock Theragra chalcogramma. Environ Biol Fishes 50: 405-413

Suriyampola PS, Shelton DS, Shukla R, Roy T, Bhat A, Martins EP (2016a) Zebrafish social behavior in the wild. Zebrafish 13:1-8

Suriyampola PS, Sykes DJ, Khemka A, Shelton DS, Bhat A, Martins EP (2016b) Water flow impacts group behavior in zebrafish (Danio rerio). Behav Ecol,

*Viscido SV, Parrish JK, Grünbaum D (2004) Individual behavior and emergent properties of fish schools: a comparison of observation and theory. Mar Ecol Prog Ser 273:239-249

*Wong MYL (2011) Group size in animal societies: the potential role of social and ecological limitations in the groupliving fish, Paragobiodon xanthosomus. Ethology 117: 638-644

Yan GJ, He XK, Cao ZD, Fu SJ (2013) An interspecific comparison between morphology and swimming performance in cyprinids. J Evol Biol 26:1802-1815

Submitted: July 20, 2016; Accepted: November 14, 2016

Proofs received from author(s): December 2, 2016 